\title{
Influence of Scheduled Analgesics Administration on Surgical Patients' Pain Relief in Teaching Hospitals in Port Harcourt, Nigeria
}

\author{
Esther E. Nwaomah $^{1} \quad$ Yemisi T. Babalola $^{2} \quad$ Rasidi A. Salawu $^{1}$ \\ 1.Adult Health Department, School of Nursing Science, Babcock University, Ilishan Remo, Ogun State, Nigeria \\ 2.Head of Department, Information Resources Management, School of Management Sciences, Babcock \\ University, Ilishan Remo, Ogun State, Nigeria
}

\begin{abstract}
Pain is a serious problem for surgical patients during the post-operative period. Surgical patients receiving analgesics for pain management after surgery expect to achieve pain relief. However, current evidence revealed that some patients in teaching hospitals in Port Harcourt do not achieve pain relief during the post-operative period. When patients do not achieve pain relief, they could become upset and frustrated with the care they received, leading to complaints and damage to the reputation of the teaching hospitals. Hence, this study determined the influence of scheduled analgesics administration on surgical patients' pain relief in teaching hospitals in Port Harcourt, Nigeria.The study utilized survey research design to answer the objectives. The population was 3854 comprising 250 surgical nurses, 1802 surgical patients and 1802 medication charts in teaching hospitals in Port Harcourt. Krejcie and Morgan table was used to obtain the sample size of 152 nurses, 317 patients and 317 medication charts. Multistage sampling method was used to select the participants. A validated questionnaire which was partly adapted, and medication charts audit checklist were used for data collection. Cronbach's alpha coefficients for the constructs ranged from 0.74 to 0.90 . A response rate of $87.1 \%$ over all was achieved. Data were analyzed using descriptive and inferential statistics.Findings revealed that scheduled analgesics administration had significant positive influence on surgical patients' pain relief $\left(R^{2}=.075\right.$, $\beta=0.273, p<0.05, F(1,144)=11.626, p<0.05)$. Further findings showed that on the basis of the criterion mean of 3.0, surgical patients' level of pain relief was very high $(\mathrm{M}=1.75)$. The study concludes that scheduled analgesics administration enhances surgical patients' pain relief in teaching hospitals in Port Harcourt, Nigeria. The study recommends that surgical nurses should follow the analgesics schedule prescribed for patients after surgery to increase and sustain pain relief among surgical patients.
\end{abstract}

Keywords: Pain relief, Scheduled analgesics administration, Surgical patients, Teaching Hospitals

DOI: $10.7176 / \mathrm{JHMN} / 88-07$

Publication date: April $30^{\text {th }} 2021$

\subsection{Introduction}

Pain is an important post-operative problem that surgical patients encounter in healthcare during the postoperative period. Pain represents an unpleasant feeling affecting the body and the mind, and it is associated with existing or potential injury. Pain is the physical anguish or unpleasant sensation experienced by surgical patients at the incision site. Pain may be severe in nature, and could be characterized as burning, throbbing, biting, stinging, aching, hurting, agony, soreness and discomfort; and may be described in relation to injury; for example surgical wound (Berman, Snyder, \& Frandsen, 2016; International Association for the Study of Pain [IASP], 2012). Considering the subjective nature of pain experience and the challenge of some patients who cannot communicate their pain to the health care provider, the World Health Organization (WHO) and the International Association for the Study of Pain (IASP) have recognized pain as the fifth vital sign, making it mandatory for nurses to evaluate patients' pain regularly and to treat the pain to achieve acceptable pain relief (IASP, 2012; Potter, Perry, Stockert \& Hall, 2015).

Prompt and effective acute pain management is necessary for achieving pain relief for the surgical patient. Generally, the discomfort from severe pain can affect the individual's ability to perform important activities of daily living as well as affect emotional and physical health (Berman et al., 2016). Untreated surgical pain could become severe and progress to chronic pain (Stodart \& McCallum, 2014). Rababa (2018) reported that surgical patients with unrelieved pain often complain of poor pain management which nurses distinguish as a psychological pain and may not give prompt treatment to relieve it. Evidence further show that poor pain control can impact on the systems of the body, causing serious health problems thus increasing the risk of complications as it has potential of slowing wound healing while speeding up morbidity and mortality (Armstein, 2010; Gan, Epstein, Leone-Perkins, Salimi, Igbal \& Whang, 2018).

The problem of poor pain relief following surgical procedure is worldwide, affecting both developed and developing countries (Berman et al., 2016). Evidences from developed countries like USA, UK, Australia, Malaysia, India, and New Zealand show that effective pain relief during the post-operative period was 
problematic (Chou et al., 2016; Rababa, 2018; Stodart \& McCallum, 2014; Subramanian et al., 2017). Similar reports of disappointment with pain relief are equally available in Africa and Nigeria in particular (Githemo, Karani, Ogutu \& Gachoka, 2018; Onianwa, et al., (2017). Masigati and Chilonga (2014) studied post-operative pain management outcome in Tanzania and found that only $18(14.5 \%)$ reported absence of pain at rest during the early post-operative period. This result showed poor pain relief among the surgical patients which is unacceptable for proper recovery and functional status. The evidences cited indicate that about $50 \%$ to $80 \%$ of post-surgical patients continue to experience unacceptable pain levels despite availability of effective treatment for acute pain.

Pain elimination can be achieved through regular administration of analgesics which evidence show to have potential to relieve and prevent recurrence of pain thereby promoting patient's comfort, and functional status (Hinkle \& Cheever, 2018). Pain relief is an important indicator of the quality of care as it judges the significance of pain management provided to surgical patients (Scientific Cooperations Medical Workshops [SCMW], 2015). Evidences are in support of regularly administered analgesics for effective relief of acute surgical pain (Erskine et al., 2017; Málek et al., 2017). The term 'scheduled analgesics' refers to a pain treatment approach that involves the prescription of pain relieving medication that is given at regularly planned time intervals throughout the twenty-four hour period of the day (Morrow, 2018). The goal is to persistently relieve patient's pain and prevent recurrence. This approach is also known as 'scheduled analgesics regime', 'around-the-clock', 'scheduled regime', and 'time-contingent schedules' (Málek, et al., 2017).

However, when nurses are unable to administer analgesics as scheduled, patients suffer unjustifiably from constant pain which is usually present following surgery (Masigati \& Chilonga, 2014). Sometimes patients do not receive their pain medication on schedule because of competing responsibilities for nurses. Consequently, such patients are given their overdue analgesics when pain has already occurred. Yefet et al. (2017) argue that administration of analgesics when pain has occurred makes it problematic to achieve pain relief as it takes longer for the action of the analgesics to peak and eliminate the pain. These authors also argue that analgesics which are administered on schedule demonstrate relevance in ensuring patients' comfort and well-being during the post-operative period. Relieved pain during the post-operative period encourages patients to participate in activities of daily living such as mobility, showering, dressing, and sleeping without interruption by pain. This further supports that administration of scheduled analgesics helps to prevent poor pain relief, and encourages patients to adhere to their pain management plan. Evidence further shows that administration of sufficient dose of scheduled analgesics regularly reduces severe pain, resulting in patient needing lesser amount of the analgesics overall thereby reducing side effects and achieving optimal pain relief (Yefet et al., 2017).

Evidences in favour of scheduled analgesics administration with potential to influence surgical patients' pain relief are more abroad (Erskine, Wiffen \& Conllon, 2017; Yefet et al., 2017). These authors report that scheduled analgesics is superior to analgesics administration on demand as it leads to lower mean pain score in surgical patients. In another study in USA, Valentine and colleagues (2015) reported a reduced use of opioids after cesarean section consequent to scheduled analgesics treatment. Another study by Artime and colleagues (2018) in the State of Texas in USA reported that surgical patients who had craniotomy were satisfied with pain relief from scheduled intravenous acetaminophen.

The range of the surgical patients' pain problem is global and remarkable, with emergency and elective surgical patients adding to the burden. The problem is more critical in developing nations of the world and Nigeria is not exempt which made undertaking of the study indispensable. Up till now, according to the researcher's knowledge, there has been no study which examined the influence of scheduled analgesics administration on patients' pain relief among surgical patients in teaching hospitals in Port Harcourt. Therefore; this study investigated the influence of scheduled analgesics administration on surgical patients' pain relief in teaching hospitals in Port Harcourt.

\subsection{Research Questions}

The study responded to the following questions and tested the null hypothesis at the 0.05 level of significance.

1. What is the surgical patients' level of pain relief in teaching hospitals in Port Harcourt, Nigeria?

2. What is the frequency of scheduled analgesics administration by surgical nurses in teaching hospitals in Port Harcourt, Nigeria?

Ho: Scheduled analgesics administration has no significant influence on surgical patients' pain relief in teaching hospitals in Port Harcourt, Nigeria

\subsection{Methodology}

2.1 Research Design: This study adopted a survey method to determine the influence of scheduled analgesics administration on surgical patients' pain relief in teaching hospitals in Port Harcourt, Nigeria.

2.2 Population: The population of this study comprised surgical patients who have recently undergone surgery 
as inpatients in surgical wards and units and surgical nurses who have a minimum of six months surgical experience of working with post-operative patients, and medication charts of the surgical patients in teaching Hospitals in Port Harcourt. The total population of this study was 3854 consisting of surgical nurses, surgical patients and medication charts of surgical patients. The population of surgical nurses was 250 made up of 174 nurses from the University of Port Harcourt Teaching Hospital (UPTH) and 76 nurses from the Rivers State University Teaching Hospital (RSUTH). The population of surgical patients was composed of 959 adult surgical patients from UPTH and 843 adult surgical patients from RSUTH which made a total of 1802 . The population of medication charts is the same number as the surgical patients since it is the medication charts of the surgical patients that took part in the study which was 1802 .

Inclusion criteria: Patients were included if they had surgery and were admitted as inpatients for at least 24 hours for post-operative management and had pain experience in the past 24 hours before the commencement of data collection procedure. Nurses who work with post-operative patients and have had at least six months experience as surgical nurses and voluntarily accept to participate were included.

Exclusion criteria: Patients who had surgery but were not admitted for management of post-operative care. Patients who did not have pain in the past 24 hours and patients who did not volunteer to participate were excluded. Nurses who had less than six months surgical experience, and were on annual or maternity leave were excluded.

2.3 Sample size and Sampling technique: Krejcie and Morgan Table (1970) were used to determine the sample size for this study. The sample size of 152 surgical nurses was selected out of 250 surgical nurses in both teaching hospitals. Likewise, 317 surgical patients and 317 medication charts were respectively selected from 1802 surgical patients and medication charts from both teaching hospitals. Consequently, a total sample size of 786 comprising of 152 nurses, 317 patients and 317 medication charts were selected.

A two-stage sampling technique was used in selecting the teaching hospitals and research participants. At the first stage, purposive sampling method was used to select the two university teaching hospitals in Port Harcourt. These two hospitals were chosen because they have the type of participants deemed useful in providing relevant data for the study objectives. The second stage sampling utilized convenience technique to select 152 surgical nurses who voluntarily accepted to participate in the research according to their availability. Similarly, convenience sampling technique was used to select 317 post-operative patients who had surgery before the commencement of data collection. Convenience method was used because all the patients were not admitted to the hospital at the same time but according to the date of their surgery.

\subsection{Instrumentation}

The instrument for data collection included questionnaire for patients and nurses and medication chart audit checklist. The patient questionnaire was adapted from the Revised American Pain Society Patient Outcome Questionnaire (APS-POQ-R) (Subramanian et al., 2017). This was modified to suit the need of data collection in the context of this study and labelled 'Patients' Pain Outcome Questionnaire' (PPOQ). This scale was used to obtain data from surgical patients on their pain relief. It comprised of two sections A and B. Section A consists of socio-demographic information while section B contains items used to collect data on surgical patients' pain relief which was measured by pain score on numeric rating scale (NRS). The scale rates from ' 0 ' to ' 10 ' with ' 0 ' being no pain while ' 10 ' is the worst pain that can be felt. This scale was recoded to a 5 point scale for easy analysis and interpretation. The recoded 5 point scale was $0=$ no pain, $1-3=$ mild pain, $4-6=$ moderate pain, $7-8$ $=$ not very severe pain, and 9-10 = very severe or excruciating pain.

\subsection{Reliability of Instrument}

Face and content validity was done by expert nurses in Babcock University school of Nursing Science and nurses in Babcock University Teaching Hospital. The questionnaire was pre-tested on similar population in Babcock University Teaching Hospital (BUTH) Ilishan Remo in Ogun State and Olabisi Onabanjo University Teaching Hospital (OOUTH), Sagamu in Ogun State. These hospitals were not part of the study population. The data gathered were subjected to Cronbach's alpha reliability test. All the sections of the instrument yielded coefficients ranging from 0.74 to 0.90 . The construct validity was also done and the result showed AVE range of 0.621 to $0.810, \mathrm{KMO}, 0.516$ to 0.821 and Bartlett Test was 0.000 .

2.6 Method of Data Collection: The purpose of the study was discussed with the participants in the teaching hospitals. Informed consent was obtained before data collection. During data collection procedure, 152 copies of the nurses' questionnaire and 317 copies of patients' questionnaire were administered to surgical nurses and patients in both teaching hospitals.

2.7 Method of Data Analysis: Completed copies of the questionnaire were sorted, coded and entered into the 
computer using software Statistical Package for Social Sciences (SPSS) Version 23. Descriptive and inferential statistics were performed

2.8 Ethical Consideration: Ethical approvals were obtained from Babcock University Human Research Ethics Committee (BUHREC) and the Ethical Committees of the university teaching hospitals (UPTH and RSUTH) in Port Harcourt where the study was conducted. The participants were informed that their participation in the study was voluntary and can withdraw at any time without penalty or prejudice. Ethical principles were ensured in conducting the study. The researcher ensured that data obtained from the participants were strictly used for the study and academic purposes. Confidentiality and anonymity were guaranteed. No conflict of interest existed between the researcher, participants, and the teaching hospitals.

\subsection{Results}

The returned copies of nurses' questionnaire were 146 (96.1\%), patients' questionnaire response rate was 262 $(82.6 \%)$ and medication charts audit response rate was $262(82.6 \%)$.

Table 1: Surgical Patients' Socio-demographic Characteristics

\begin{tabular}{|c|c|c|c|}
\hline Variable & Categories & Frequency (n) & Percentage (\%) \\
\hline \multirow[t]{7}{*}{ Age } & $18-30$ years & 75 & 28.6 \\
\hline & $31-40$ years & 80 & 30.5 \\
\hline & $41-50$ years & 66 & 25.2 \\
\hline & 51- 60 years & 19 & 7.3 \\
\hline & $61-65$ years & 11 & 4.2 \\
\hline & Above 65 years & 11 & 4.2 \\
\hline & Total & 262 & 100 \\
\hline \multirow[t]{3}{*}{ Gender } & Male & 98 & 37.4 \\
\hline & Female & 164 & 62.6 \\
\hline & Total & 262 & 100 \\
\hline \multirow[t]{3}{*}{ Religion } & Christianity & 247 & 92.3 \\
\hline & Islam & 15 & 5.7 \\
\hline & Total & 262 & 100 \\
\hline \multirow[t]{8}{*}{ Surgical specialty } & General surgery & 84 & 32.1 \\
\hline & Orthorpaedic & 76 & 29.0 \\
\hline & Obstetrics \& Gynecology & 69 & 26.3 \\
\hline & ENT & 03 & 1.1 \\
\hline & Ophthalmology & 07 & 2.7 \\
\hline & Plastics and Burns & 11 & 4.2 \\
\hline & Surgical OPD & 12 & 4.6 \\
\hline & Total & 262 & 100 \\
\hline \multirow{7}{*}{$\begin{array}{l}\text { Number of days since } \\
\text { surgery in the specialty }\end{array}$} & 1-3 days & 84 & 32.1 \\
\hline & 4-6 days & 92 & 35.1 \\
\hline & $7-10$ days & 42 & 16.0 \\
\hline & $11-15$ days & 18 & 6.9 \\
\hline & $16-20$ days & 13 & 5.0 \\
\hline & 20 days and above & 13 & 5.0 \\
\hline & Total & 262 & 100 \\
\hline \multirow[t]{6}{*}{ Highest education attained } & Primary & 08 & 3.1 \\
\hline & Secondary & 46 & 17.6 \\
\hline & Post-secondary & 59 & 22.5 \\
\hline & Tertiary & 145 & 55.3 \\
\hline & Others & 04 & 1.5 \\
\hline & Total & 262 & 100 \\
\hline \multirow[t]{5}{*}{ Employment status } & Unemployed & 35 & 13.4 \\
\hline & Civil servant & 122 & 46.5 \\
\hline & Self-employed & 84 & 32.1 \\
\hline & Others & 21 & 8.0 \\
\hline & Total & 262 & 100 \\
\hline
\end{tabular}

Table 1: revealed that $155(59.1 \%)$ of the surgical patients who responded were between the range of 18 and 40 years, which signifies energetic working age group. One hundred and sixty four (62.6\%) respondents were 
female while 98 (37.4\%) were males. This suggests that there were more females than males visiting teaching hospitals in Port Harcourt. The reason for higher percentage of female respondent could be attributed to surgeries related to obstetrics and gynaecology which exclusively pertain to women. Table 1 also revealed that $247(92.3 \%)$ of surgical patients visiting teaching hospitals in Port Harcourt were Christians. This was not surprising as Rivers State is predominantly Christian population.

Findings further showed that $84(32.1 \%), 76(29.0 \%)$ and $69(26.3 \%)$ of surgical patients respectively visited general surgery, orthorpaedic and obstetrics and gynecology departments of teaching hospitals in Port Harcourt. This result suggests that general surgery, orthorpaedic, obstetrics and gynecology departments were the busiest units of the teaching hospitals. Findings also showed that 31(11.9\%) of patients spent between 11 to 20 days in-patients in the specialties in the teaching hospitals. This suggests that surgical patients admitted in teaching hospitals in Port Harcourt stay longer to receive sufficient treatment for proper healing. Another implication could be that the type of surgery undertaken demanded longer period of time to heal. For instance, orthorpaedic patients may stay longer than obstetrics patients. The length of stay was necessary to provide efficient post-operative care to enhance pain relief.

Table 2: Surgical Nurses' Socio-demographic Characteristics

\begin{tabular}{|c|c|c|c|}
\hline Variable & Categories & Frequency (n) & Percentage (\%) \\
\hline \multirow[t]{6}{*}{ Age } & $21-30$ years & 28 & 19.2 \\
\hline & $31-40$ years & 47 & 32.2 \\
\hline & $41-50$ years & 39 & 26.7 \\
\hline & $50-50$ years & 29 & 19.8 \\
\hline & $61-65$ years & 03 & 2.1 \\
\hline & Total & 146 & 100 \\
\hline \multirow[t]{3}{*}{ Gender } & Male & 14 & 9.6 \\
\hline & Female & 132 & 90.4 \\
\hline & Total & 146 & 100 \\
\hline \multirow[t]{3}{*}{ Religion } & Christianity & 142 & 97.3 \\
\hline & Islam & 04 & 2.7 \\
\hline & Total & 146 & 100 \\
\hline \multirow[t]{8}{*}{ Surgical specialty } & General surgery & 56 & 38.4 \\
\hline & Orthorpaedic & 21 & 14.4 \\
\hline & Obstetrics \& Gynecology & 43 & 29.5 \\
\hline & ENT & 03 & 2.1 \\
\hline & Ophthalmology & 02 & 1.4 \\
\hline & Plastics and Burns & 14 & 9.6 \\
\hline & Surgical OPD & 07 & 4.8 \\
\hline & Total & 146 & 100 \\
\hline \multirow{7}{*}{ Years in the specialty } & $1-2$ years & 55 & 37.7 \\
\hline & $3-5$ years & 34 & 23.3 \\
\hline & $6-10$ years & 25 & 17.1 \\
\hline & $11-15$ years & 09 & 6.2 \\
\hline & $16-20$ years & 09 & 6.2 \\
\hline & 20 years and above & 14 & 9.6 \\
\hline & Total & 146 & 100 \\
\hline \multirow[t]{6}{*}{ Years in service } & $1-4$ years & 37 & 25.3 \\
\hline & $5-10$ years & 32 & 21.9 \\
\hline & $11-15$ years & 32 & 21.9 \\
\hline & $16-20$ years & 17 & 11.6 \\
\hline & 21 years and above & 28 & 19.2 \\
\hline & Total & 146 & 100 \\
\hline \multirow[t]{5}{*}{ Professional qualification } & Nurses with one qualification & 39 & 26.7 \\
\hline & Nurses with two qualifications & 59 & 40.4 \\
\hline & Nurses with three qualifications & 44 & 30.1 \\
\hline & Nurses with four qualifications & 4 & 2.7 \\
\hline & Total & 146 & 100 \\
\hline
\end{tabular}

Table 2: revealed that $75(51.4 \%)$ of the respondents were between the range of 21 and 40 years, which signifies youthful and prime age for work. This result suggests that half of the surgical nurses working in teaching hospitals in Port Harcourt are in active age. Findings show that 132(90.4\%) of the nurses were females 
while $14(9.6 \%)$ were males. This indicates the presence of more female nurses than males working in teaching hospitals in Port Harcourt. This result is expected because the nursing profession is female denominated. Moreover, the table revealed that $142(97.3 \%)$ of surgical nurses in teaching hospitals in Port Harcourt were Christians. This is expected as Rivers State is predominantly Christian. Findings further revealed that 114(78.1\%) of surgical nurses in teaching hospitals in Port Harcourt had one to 10 years work experience in their specialty. This suggests that the nursing staff in the teaching hospitals have sufficient experience in their specialty which enabled them perform their scheduled analgesics administration duties effectively.

Likewise, 101(69.1\%) of surgical nurses in teaching hospitals in Port Harcourt had one to 15 years in the service. This suggests that the nursing workforce in Port Harcourt teaching hospitals have remained stable in the health sector which implies that they have considerable experience to enable them efficiently manage patients' post-operative pain. Furthermore, $107(73.2 \%)$ of surgical nurses in the teaching hospitals had at least two professional qualifications in the field of nursing. This implied that surgical nurses in the various surgical departments in the teaching hospitals have varied experiences and skills to care for different needs of postoperative patients including pain management that enhances patients' pain relief.

Research Question One: What is the surgical patients' level of pain relief in teaching hospitals in Port Harcourt?

Table 3: Surgical Patients' Level of Pain Relief in Teaching Hospitals in Port Harcourt

\begin{tabular}{|c|c|c|c|c|c|c|c|}
\hline Pain Relief & $\begin{array}{c}\text { No } \\
\text { Pain(1) }\end{array}$ & $\begin{array}{l}\text { Mild } \\
\text { Pain } \\
(2)\end{array}$ & $\begin{array}{l}\text { Moderate } \\
\text { Pain } \\
\text { (3) }\end{array}$ & $\begin{array}{l}\text { Not very } \\
\text { Severe } \\
\text { Pain } \\
\text { (4) }\end{array}$ & $\begin{array}{l}\text { Severe } \\
\text { Pain } \\
\text { (5) }\end{array}$ & Mean & $\begin{array}{l}\text { Std. } \\
\text { Dev. }\end{array}$ \\
\hline $\begin{array}{l}\text { Severity of pain (decrease } \\
\text { in pain) }\end{array}$ & & & & & & 2.58 & 0.61 \\
\hline $\begin{array}{l}\text { On this scale, please tick }[\sqrt{ }] \\
\text { the worst pain you had in the } \\
\text { past } 24 \text { hours }\end{array}$ & $02(0.8)$ & $38(14.5)$ & $101(38.5)$ & $84(32.1)$ & $37(14.1)$ & 3.44 & 0.93 \\
\hline $\begin{array}{l}\text { In the past } 24 \text { hours what is } \\
\text { the percentage of pain relief } \\
\text { you achieved from your } \\
\text { regular analgesics? }\end{array}$ & 0 & $10(3.8)$ & $123(46.9)$ & $88(33.6)$ & $41(15.6)$ & 2.61 & 0.79 \\
\hline $\begin{array}{l}\text { Please tick }[\sqrt{ }] \text { the number that } \\
\text { shows the pain you feel while } \\
\text { trying to move in bed }\end{array}$ & $20(7.6)$ & $127(48.6)$ & $87(33.2)$ & $25(9.5)$ & $03(1.1)$ & 2.48 & 0.82 \\
\hline $\begin{array}{l}\text { On this scale, Please tick }[\sqrt{ }] \\
\text { the least pain you had in the } \\
\text { past } 24 \text { hours }\end{array}$ & $12(4.6)$ & $163(62.2)$ & $80(30.5)$ & $07(2.7)$ & 0 & 2.31 & 0.60 \\
\hline $\begin{array}{l}\text { Please tick }[\sqrt{ }] \text { the number that } \\
\text { shows the pain you feel while } \\
\text { lying in bed resting without } \\
\text { moving }\end{array}$ & $73(27.9)$ & $122(46.6)$ & $45(17.1)$ & $22(8.4)$ & 0 & 2.06 & 0.89 \\
\hline $\begin{array}{l}\text { How often were you in severe } \\
\text { pain in the past } 24 \text { hours? }\end{array}$ & $83(31.7)$ & $106(40.5)$ & $61(23.3)$ & $09(3.4)$ & $03(1.1)$ & 2.02 & 0.89 \\
\hline $\begin{array}{l}\text { Activities Associated with } \\
\text { Pain: } \\
\text { Please indicate how pain } \\
\text { prevents you from doing any } \\
\text { of the following activities in } \\
\text { the past } 24 \text { hours: }\end{array}$ & & & & & & 1.85 & 0.85 \\
\hline $\begin{array}{l}\text { Doing activities out of bed } \\
\text { such as walking, sitting in a } \\
\text { chair, changing clothes }\end{array}$ & $54(20.6)$ & $115(43.9)$ & $67(25.6)$ & $21(8.0)$ & $05(1.9)$ & 2.27 & 0.94 \\
\hline $\begin{array}{l}\text { Doing activities in bed such as } \\
\text { turning, sitting up, } \\
\text { repositioning }\end{array}$ & $91(34.8)$ & $99(37.8)$ & $52(19.8)$ & $15(5.7)$ & $05(1.9)$ & 2.02 & 0.98 \\
\hline Falling asleep & $130(49.6)$ & $78(29.8)$ & $36(13.7)$ & $13(5.0)$ & $05(1.9)$ & 1.80 & 0.98 \\
\hline Remaining asleep & $154(58.8)$ & $63(24.0)$ & $30(11.4)$ & $13(5.0)$ & $02(0.8)$ & 1.65 & 0.92 \\
\hline
\end{tabular}




\begin{tabular}{|l|l|l|l|l|l|l|c|}
\hline $\begin{array}{l}\text { Emotions Associated with } \\
\text { Pain: }\end{array}$ & & & & & & & \\
$\begin{array}{l}\text { How much did you feel any of } \\
\text { these emotions because of } \\
\text { your pain: }\end{array}$ & & & & & & & \\
\hline Anxious & $206(78.6)$ & $34(13.0)$ & $15(5.7)$ & $05(1.9)$ & $02(0.8)$ & 1.33 & 0.74 \\
\hline Helpless & $217(82.8)$ & $22(8.5)$ & $15(5.7)$ & $05(1.9)$ & $02(1.1)$ & 1.30 & 0.76 \\
\hline Frightened & $219(83.6)$ & $20(7.6)$ & $14(5.4)$ & $06(2.3)$ & $03(1.1)$ & 1.30 & 0.77 \\
\hline Depressed & $225(85.9)$ & $17(6.6)$ & $14(5.3)$ & $03(1.1)$ & $03(1.1)$ & 1.25 & 0.72 \\
\hline $\begin{array}{l}\text { Side Effects of Analgesia: } \\
\text { Please indicate the frequency } \\
\text { you have experienced any of } \\
\text { the following side effects from } \\
\text { your analgesics in the past 24 } \\
\text { hours: }\end{array}$ & & & & & & & \\
\hline Dizziness & & & & & & & \\
\hline Drowsiness & $200(76.3)$ & $37(14.1)$ & $17(6.5)$ & $02(0.8)$ & $06(2.3)$ & 1.39 & 0.83 \\
\hline Nausea & $201(76.7)$ & $36(13.7)$ & $21(8.0)$ & $02(0.8)$ & $02(0.8)$ & 1.35 & 0.73 \\
\hline Itching & $199(76.0)$ & $50(19.1)$ & $10(3.8)$ & 0 & $03(1.1)$ & 1.31 & 0.66 \\
\hline Average Weighted Mean & $234(89.6)$ & $19(7.3)$ & $07(2.7)$ & $01(0.4)$ & 0 & 1.14 & 0.44 \\
\hline
\end{tabular}

Pain outcome scale was recoded as: $0=0$ (no pain), $1-3=1$ (mild pain), 4-6=3 (moderate pain), $7-8=4$ (not very severe pain), 9-10 $=5$ (severe pain) based on Subramanian et al., (2017) suggestion.

\section{Decision Rule: If mean is...}

4.21 to $5.0=$ Severe pain (very low pain relief)

3.41 to $4.20=$ Not very severe pain (low pain relief)

2.61 to $3.40=$ Moderate pain (moderate pain relief)

1.81 to $2.60=$ Mild pain (high pain relief)

1.0 to $1.80=$ No pain (Very high pain relief)

Criterion Mean $=3.0$

Table 3 showed that the level of surgical patients' pain relief was very high. The items used to measure pain relief were severity of pain, activities associated with pain, emotions associated with pain and side effects of analgesics. Out of the components of pain outcome, severity of pain had the highest mean score $(\mathrm{M}=2.58)$, followed by activities associated with pain $(M=1.85)$, emotions associated with pain $(M=1.32)$, while side effects of analgesics had the lowest mean score $(M=1.23)$. These results suggest that most of the surgical patients in teaching hospitals in Port Harcourt had very high level of pain relief. The Average Weighted Mean Score of 1.75 falls below the criterion Mean of 3.0 and clearly showed that the surgical patients' level of pain relief was very high. Although, the level of emotions associated with pain and side effects associated with analgesics were low, the worst pain encountered by surgical patients were high with mean $(M=3.44)$. 
Research Question Two: What is the frequency of scheduled analgesics administration by surgical nurses in teaching hospitals in Port Harcourt?

Table 4: Frequency of scheduled analgesics administration by surgical nurses in Teaching Hospitals in Port Harcourt

\begin{tabular}{|c|c|c|c|c|c|c|}
\hline $\begin{array}{l}\text { Scheduled analgesics administration: } \\
\text { In your role as a nurse, indicate the } \\
\text { frequency at which you: }\end{array}$ & $\begin{array}{c}\text { Every } \\
\text { Time (4) }\end{array}$ & Often (3) & $\begin{array}{c}\text { Sometimes } \\
\text { (2) }\end{array}$ & $\begin{array}{l}\text { Never } \\
\text { (1) }\end{array}$ & Mean & $\begin{array}{l}\text { Std. } \\
\text { Dev. }\end{array}$ \\
\hline $\begin{array}{l}\text { give the right dose of analgesic in the } \\
\text { right form }\end{array}$ & $\begin{array}{l}124 \\
(84.9)\end{array}$ & $9(13.0)$ & $03(2.1)$ & 0 & 3.83 & 0.43 \\
\hline give the analgesic through the right route & $\begin{array}{l}126 \\
(83.6)\end{array}$ & $13(8.9)$ & $07(4.8)$ & 0 & 3.82 & 0.50 \\
\hline $\begin{array}{l}\text { ensure the right analgesic medication is } \\
\text { given }\end{array}$ & $\begin{array}{l}122 \\
(82.6)\end{array}$ & $\begin{array}{l}20 \\
(13.6)\end{array}$ & $03(2.1)$ & $01(0.7)$ & 3.80 & 0.49 \\
\hline $\begin{array}{l}\text { give the right analgesic to the right } \\
\text { patient }\end{array}$ & $122(82.6)$ & $19(13.0)$ & $02(4.1)$ & 0 & 3.79 & 0.50 \\
\hline $\begin{array}{l}\text { document administration of analgesic in } \\
\text { patient's medication administration sheet } \\
\text { immediately after patient has ingested the } \\
\text { drug }\end{array}$ & $114(78.1)$ & $29(19.8)$ & $02(1.4)$ & $01(0.7)$ & 3.75 & 0.51 \\
\hline give the analgesic at the right time & $111(76.5)$ & $21(14.6)$ & $13(8.9)$ & 0 & 3.68 & 0.63 \\
\hline $\begin{array}{l}\text { stay with the patient until analgesic has } \\
\text { been swallowed/injection given }\end{array}$ & $88(60.3)$ & $38(26.0)$ & $20(13.7)$ & 0 & 3.47 & 0.73 \\
\hline $\begin{array}{l}\text { give analgesic based on appropriate pain } \\
\text { assessment data }\end{array}$ & $79(54.1)$ & $42(28.8)$ & $25(17.1)$ & 0 & 3.37 & 0.76 \\
\hline Average Weighted Mean & & & & & 3.78 & 0.39 \\
\hline
\end{tabular}

Decision Rule: If mean is 3.25-4.0 = Every Time; 2.5-3.24 = Often; 1.75-2.49 = Sometimes; 1.0-1.74 = Never

Criterion Mean $=\mathbf{2 . 5}$

Table 4: Presents the result of question two where respondents were asked to indicate the frequency of performing the responsibilities related to scheduled analgesics administration in teaching hospitals in Port Harcourt. The result showed that the overall frequency of scheduled analgesics administration was measured to be 'Every Time'. This is because most of the nurses responded that they administered scheduled analgesics frequently as evidenced from the lowest percentage of $79(54.1 \%)$ and an overall mean $(\mathrm{M}=3.78)$. This is the reflection of their responses to each statement on scheduled analgesics administration where the least mean is (M $=3.37$ ). This shows that surgical nurses in teaching hospitals in Port Harcourt consistently carried out the responsibility involved with administration of scheduled analgesics every time. This implies a high level of professional practice with respect to administration of scheduled analgesics to surgical patients for post-operative pain management in teaching hospitals in Port Harcourt. Hence, the result suggests that surgical nurses working in teaching hospitals in Port Harcourt should sustain scheduled analgesics administration in the identified areas to maintain the current level of surgical patients' pain relief. However, attention should be given to giving analgesics based on appropriate pain assessment data and staying with the patient until analgesics have been swallowed in teaching hospitals in Port Harcourt.

\section{Test of Hypotheses}

Ho1: Scheduled analgesics administration has no significant influence on surgical patients' pain relief in teaching hospitals in Port Harcourt

This null hypothesis was tested using simple linear regression analysis after strict observance of statistical prerequisites. The result of the regression analysis is presented in Table 5.

Table 5: Influence of scheduled analgesics administration on patients' pain relief

\begin{tabular}{|c|c|c|c|c|c|}
\hline . & $\mathbf{B}$ & Std. Error & Beta $(\beta)$ & $\mathbf{T}$ & Sig. \\
\hline (Constant) & 2.074 & .324 & & 6.398 & .000 \\
\hline Scheduled analgesics administration & .159 & .047 & .273 & 3.410 & .001 \\
\hline \multicolumn{6}{|l|}{ Dependent Variable: Patients' pain relief } \\
\hline $\begin{array}{l}R^{2}=.075 \\
R^{2}=.068, \text { Adjusted } \\
F=11.626 \\
D F=1,144 \\
P<.05\end{array}$ & & & & & \\
\hline
\end{tabular}


The result of Table 5 revealed that scheduled analgesics administration $\left(R^{2}=.075, \beta=0.273, p<0.05\right)$ significantly influenced surgical patients' pain relief in teaching hospitals in Port Harcourt $(F(1,144)=11.626, p$ $<0.05$ ). Therefore, the null hypothesis was rejected. However, the independent variable (scheduled analgesics administration) explained $7.5 \%$ of the change in the dependent variable (surgical patients' pain relief). This result suggests that surgical patients' pain relief can be achieved when nurses consistently administer prescribed analgesics on schedule. Hence, human resource policies that can enhance nurses' capacity to accurately, consistently and deliberately administer scheduled analgesics should be put in place to sustain patients' pain relief. This would require reducing the workload by increasing the nurse-patient ratio to enable time for properly attending to patients during administration of scheduled analgesics to consistently achieve pain relief.

\subsection{Discussion of Findings}

This study examined nurses' administration of scheduled analgesics administration to surgical patients during post-operative pain management, and how scheduled analgesics administration influences surgical patients' pain relief in teaching hospitals in Port Harcourt, Nigeria. The result of question one showed that surgical patients' level of pain relief in teaching hospitals in Port Harcourt was very high, on a scale of 5. This finding agrees with the finding of studies conducted by Schroeder (2016) in USA and Mubita et al. (2019) in UK that reported majority of patients indicated pain relief from their pain management. Conversely, the result of this study disagrees with earlier studies which revealed that pain management strategies have been improved in recent times but these have not transformed to surgical patients' pain relief (Chou et al., 2016; Stodart \& McCallum, 2014; Subramanian et al., 2017). The difference in results could be due to the different participants used in the present study. This may have been as a result of the nurses who were highly proficient in the administration of scheduled analgesics to the surgical patients who participated in this study. Other studies have reported varying accounts of pain relief that were acceptable to patients and pain perception in surgical patients (Chung \& Liu, 2011; Donovan, 1983; Weis et al., 2003). As a result, it is germane for the teaching hospitals in Port Harcourt to endeavour to sustain surgical patients' level of pain relief.

Findings also showed that the overall frequency of scheduled analgesics administration was every time. This suggests that surgical nurses administered scheduled analgesics regularly according to prescription which enhanced patients' pain relief. This result agrees with the study by Artime and colleagues (2018) which argue that if analgesics are given on regular basis, pain relief would be sustained. On the contrary, the findings of this study does not support an earlier study by Chin and colleagues (2013) which reported that using scheduled analgesics did not improve pain score, but results in faster and more complete functional outcomes.

The result of the test of hypothesis revealed that scheduled analgesics administration significantly influenced surgical patients' pain relief in teaching hospitals in Port Harcourt.

This finding agrees with earlier studies by Artime et al., (2018) in Texas, USA and Valentine et al., (2015) also in USA. The study by Artime et al., (2018) reported that the group taking scheduled intravenous acetaminophen showed significantly improved surgical patients' pain relief overall during postoperative pain management. While Valentine et al. (2015) identified that scheduled analgesics were more effective in controlling patients' pain after surgery.

\subsection{The Major Findings of the Study are here outlined:}

I. Pain relief was highly reported among surgical patients' in teaching hospitals in Port Harcourt, Nigeria.

II. The overall frequency of scheduled analgesics administration was regular in teaching hospitals in Port Harcourt, Nigeria.

III. Scheduled analgesics administration significantly influenced patients' pain relief in teaching hospitals in Port Harcourt, Nigeria.

\subsection{Recommendations}

Based on the findings reported, the following recommendations are submitted:

1. The head of nursing services (HNS) in teaching hospitals in Port Harcourt should ensure that surgical nurses pay particular attention to assessing surgical patients for worst pain that they encounter daily despite receiving scheduled analgesics in order to enhance their pain relief.

2. The clinical directors of the teaching hospitals in Port Harcourt should implement the policy that requires nurses to stay with patients until oral analgesics are swallowed to enhance effectiveness of analgesics in teaching hospitals in Port Harcourt.

3. The directors of nursing in each surgical specialty in the teaching hospitals should ensure that nurses reassess patients after administration of scheduled analgesics as this evaluation enables confirmation of the effect of analgesics and ascertain pain relief. 


\subsection{Suggestions for further studies}

This study was conducted among surgical patients and nurses in surgical specialties in teaching hospitals in Port Harcourt, Nigeria.

1. This study could be replicated in other metropolitan cities in Nigeria to establish the influence of scheduled analgesics administration on surgical patients' pain relief.

2. Other studies could be conducted on the influence of medication administration on the treatment of diverse diseases for example antibiotics in infectious diseases.

3. The scheduled analgesics administration instrument could be used to investigate similar studies in another context to assess the validity of the instrument.

\subsection{Conclusion}

This study investigated the influence of scheduled analgesics administration on surgical patients' pain relief in teaching hospitals in Port Harcourt, Nigeria. The result of the study show that scheduled analgesics administration influenced surgical patients' pain relief. Findings of this study further revealed that surgical patients in teaching hospitals in Port Harcourt reported very high level of pain relief. Pain relief is indispensable after surgery. This is extremely important so that patients can achieve comfort and wellbeing to enable effective participation in activities of daily living. Pain relief is also important for patients as it facilitates mobility, deep breathing and coughing which assist in the prevention of complications associated with unrelieved pain such as chest infection, pulmonary thrombosis and other circulatory problems. Pain has adverse effects on personal life in the areas of sleep, emotion, appetite and recovery from surgery. Although literature identifies growing evidence on pain management, but pain is still a prevalent problem that needs more attention and evaluation. Identified barriers that hamper sustained pain relief in surgical patients must be overcome. Active involvement of patients in the planning and implementation of scheduled analgesics administration must be encouraged. Thus, teaching hospitals and other health institutions should place their emphasis on a continual evaluation of patients for worst pain despite the administration of analgesics. Our findings in this study may help build the knowledge base on surgical patients' pain relief.

\section{References}

Armstein, P. C. (2010). Clinical Coach for Effective Pain Management. Philadelphia, PA: F. A. Davis.

Berman, A., Snyder, S. \& Frandsen, G. (2016). Kozier \& Erb's Fundamentals of Nursing: Concepts, Process \& Practice. Philadelphia, PA: Pearson Education Inc

Chin, R. P., Ho, C., \& Cheung, L. P. (2013). Scheduled analgesic regimen improves rehabilitation after hip fracture surgery. Clinical Orthorpaedic and Related Research, 471(7), 2349-2360.

Chou, R., Gordon, D. B., Leon-Casasola, O. A., Rosenberg, J. M., Bickler, S., Brennan, T., et al., (2016). Guidelines on the management of postoperative pain: A clinical practice guideline from the American Pain Society, the American Society of Regional Anesthesia \& Pain Medicine, and the American Society of Anesthesiologists' Committee on Regional Anesthesia, Executive Committee, and Administrative Council. The Journal of Pain, 17(2), 131-157.

Chung, J. W., \& Lui, J. C. (2003). Postoperative pain management: study of patients' level of pain and satisfaction with health care providers' responsiveness to their reports of pain. Nursing and Health Science, $5(1), 13-21$.

Cronbach, L. (1951). Coefficient alpha and the internal structure of tests. Psychometrika,16, 297-334.

Donovan, B. D. (1983). Patient attitudes to postoperative pain relief. Anaesthesiology Intensive Care, 11(2), $125-129$.

Ellis, D. (1989). A behavioural model for information retrieval system design. Journal of Science, 15(4-5), 237247.

Erskine, A., Wiffen, P.J., \& Conlon, J. A. (2015). As required versus fixed schedule analgesic administration for postoperative pain in children. Cochrane Data base of Systematic Reviews, 2, CD011404. DOI: 10.1002/14651858.CD011404.pub2.

Gan, T. J., Epstein, R. S., Leone-Perkins, M. L., Salimi, T., Igbal, S. U., \& Whang, P. G. (2018).Practice Patterns and Treatment Challenges in Acute Postoperative Pain Management: A Survey of Practicing Physicians. Pain Ther, 7, 205-216. https://doi.org/10.1007/s40122-018-0106-9

Githemo, G. K., Karani, A. K., Ogutu, M., \& Gachoka, H. (2018). Evaluation of patient Satisfaction with nursing care at two public hospitals in Kenya: An interventional study.Nursing \& Healthcare International Journal, $2(4), 1-8$.

Hannah, M. N., González-Fernández, M., Barret, A. D., Williams, K. A., \& Pronovost, P. (2012).Does patient perception of pain control affect patient satisfaction across surgical units in a tertiary teaching hospital? American Journal of Medical Quality, 27(5), 411-416.

Hinkle, J. L. \& Cheever, K. H. (2018). Brunner \& Suddarth's Textbook of Medical - SurgicalNursing (14 ${ }^{\text {th }}$ Ed). 
Philadelphia, PA: Wolters Kluwer/Lippincott Williams \& Wilkins.

Huvila, I. (2008). The information condition: information use by archaeologists in labour, work and action. Information Research, 13(4), 369.

International Association for the Study of Pain (2012). IASP Taxonomy. Retrieved from http://www,iasppain.org/Education/Content.aspx?itemNumber 1698.

Krejcie, R. V. \& Morgan, D. W. (1970). Determining sample size for research activities. Educational and Psychological Measurement, 30, 607- 610.

Kumar, K. H. \& Elavarasi, P. (2016). Definition of pain and classification of pain disorders. Journal of Advanced Clinical and Research Insights, 3(3), 87-90.

Málek, J., Ševčík, P., Bejšovec, D., Gabrhelík, T., Hnilicová, M., Křikava, I., et al., (2017). Postoperative Pain Management. (Eds.). Mezi Vodami: Mladá fronta a. s., Translation: Magdaléna Nováková. www.mf.cz

Masigati, H. G. \& Chilonga, K. S. (2014). Postoperative pain management outcomes among adults treated at a tertiary hospital in Moshi, Tanzan

Morrow, A. (2018). Around-the-Clock (ATC) Medication. Retrieved from https://www.verywellhealth.com/around-the-clock-atc-medication-1132176

Mubita, W. M., Richardson, C. \& Briggs, M. (2019). Patient satisfaction with pain relief following major abdominal surgery is influenced by good communication, pain relief and empathic caring: a qualitative interview study. British Journal of Pain, 14(1), 14-22.

Onianwa, P. O., Alonge, T. O., Otegbayo, J. A., Ike, E. U., Chukura, O. O., Akanbi, F. O. M.,et al. (2017). Pain as 5th vital sign: impact of pain assessment training program on Nigerian nurses' knowledge of pain management. International Journal of Midwifery, 9 (11), 129-135. Doi: 10.5897/IJNM2017.0283

Pillai Riddell, R. R. \& Craig, K. D. (2003). Time-contingent schedules for postoperative analgesia: A review of the literature. The Journal of Pain, 4(4), 169-175. Doi:10.10.1016/S1526-5900(03)00558-3

Phillips, S., Gift, M., Gelot, S., Duong, M., \& Tapp, H. (2013). Assessing the relationship between the level of pain control and patient satisfaction. Journal of Pain Research, 6, 683-689.

Potter, P. A., Perry, A. G., Stockert, P. A., \& Hall, A. (2015). Essentials for nursing practice ( ${ }^{\text {th }}$ Ed.). St Louis; Missouri: Elsevier Mosby.

Rababa, M. (2018). The role of Nurses' uncertainty in decision-making process of pain management in people with dementia. Pain Research and Treatment, 2018, 1-7. https//doi.org/10.1155/2018/7281657

Schroeder, D. L., Hoffman, L. A., Fioravanti, M., Medley, D. P., Zullo, T. G., \& Tuite, P. K. (2016). Enhancing nurses' pain assessment to improve patient satisfaction. Orthorpaedic Nursing, 35(2), 108-117.

Scientific Cooperations Medical Workshops, (SCMW), 21-22 July (2015). Assessment of patient satisfaction with acute pain management service: Monitoring quality of care in clinical setting. Istanbul; Turkey.

Stodart, K, \& McCallum, K. (2014). Take away the pain. Kai Tiaki Nursing New Zealand, 20(6), 14-16.

Subramanian, B., Shastri, N., Aziz, L., Gopinath, R., Karlekar, A., Mehta, Y. . . . Jain, P. (2017). ASSISTPatient satisfaction survey in postoperative pain management from Indian Subcontinent. Journal of Anaesthesiology Clinical Pharmacology, 30, 40-47. DOI: 10.4103/joacp.JAOCP_245_16

Yefet, E., Taha, H., Salim, R., Hasanein, J., Carmeli, Y., Schwartz, N., Nachum, Z. (2017). Fixed

Time interval compared with on-demand oral analgesia protocols for post-Caesarean Pain: A randomized control trial. General Obstetrics. 